\title{
Modification of Human-Biometeorologically Significant Radiant Flux Densities by Shading as Local Method to Mitigate Heat Stress in Summer within Urban Street Canyons
}

\author{
Hyunjung Lee, ${ }^{1}$ Jutta Holst, ${ }^{2}$ and Helmut Mayer ${ }^{1}$ \\ ${ }^{1}$ Albert-Ludwigs University of Freiburg, Werthmannstraße 10, 79098 Freiburg, Germany \\ ${ }^{2}$ Department of Physical Geography and Ecosystem Science, Lund University, Sölvegatan 12, 22362 Lund, Sweden \\ Correspondence should be addressed to Hyunjung Lee; hyunjung.lee@meteo.uni-freiburg.de
}

Received 8 April 2013; Revised 31 May 2013; Accepted 7 June 2013

Academic Editor: Tzu-Ping Lin

Copyright ( $\odot 2013$ Hyunjung Lee et al. This is an open access article distributed under the Creative Commons Attribution License, which permits unrestricted use, distribution, and reproduction in any medium, provided the original work is properly cited.

Increasing heat will be a significant problem for Central European cities in the future. Shading devices are discussed as a method to mitigate heat stress on citizens. To analyze the physical processes, which are characteristic of shading in terms of urban humanbiometeorology, experimental investigations on the thermal effects of shading by a building and shading by tree canopies were conducted in Freiburg (Southwest Germany) during typical Central European summer weather. Urban human-biometeorology stands for the variables air temperature $T_{a}$, mean radiant temperature $T_{\mathrm{mrt}}$, and physiologically equivalent temperature PET, that is the human-biometeorological concept to assess the thermal environment which was applied. The measuring setup consists of specific human-biometeorological stations, which enable the direct or indirect determination of $T_{a}, T_{\mathrm{mrt}}$, and PET. With respect to both shading devices, the $T_{a}$ reduction did not exceed $2^{\circ} \mathrm{C}$, while PET as a measure for human heat stress was lowered by two thermal sensation steps according to the ASHRAE scale. As $T_{\text {mrt }}$ has the role of a key variable for outdoor thermal comfort during Central European summer weather, all radiant flux densities relevant to the determination of $T_{\text {mrt }}$ were directly measured and analyzed in detail. The results show the crucial significance of the horizontal radiant flux densities for $T_{\text {mrt }}$ and consequently PET.

\section{Introduction}

Severe heat in summer is currently a problem for Central European cities, as both their design and citizens are not adapted to this meteorological hazard $[1,2]$. For the future, results of regional climate simulations $[3,4]$ project not only a continuation of the long-term increase of near-surface air temperature $T_{a}$ but also embedded heat waves, which will be more frequent and intense as well as lasting longer. The increasing severe heat will enhance the previous thermal strain for citizens into a considerable thermal stress, which causes extremely negative impacts on their efficiency, wellbeing, and health [5]. For example, the list of heat events during the period 2000-2007 [6] shows that the mortality rate in consequence of the heat wave of 2003 in Western Europe amounted to 19.490 in France and 5.250 in Germany. The demographic change in Central Europe is reflected by the age distribution of its population. Related to Germany, the percentage of people $\geq 65$ years was $20 \%$ in 2008 and will be $29 \%$ in 2030 [7]. This development, which is similar to other countries in Central Europe, shows a gradual increase in elderly people; that is, the human vulnerability of risk groups with respect to severe heat is rising. Thereby, the accumulation impact of longer lasting heat on citizens has to be taken into account.

Given this background, urban planning faces the huge challenge to develop, apply, and validate methods to maintain human thermal comfort for citizens even under severe heat. It must be noted that severe heat is a regional phenomenon, which depends on the large-scale weather situation. The planning methods should include a redesign of buildings, streets, and open spaces in a preventive way that severe heat can be mitigated on the local urban scale $[8,9]$. In this context, it has to be discussed whether these methods can be applied to Central European cities and to what extent [10]. Due to meteorological reasons, the assumption suggests that they will be 
more effective for dry heat than humid heat periods. The scope of urban planning to reduce severe humid heat impacts on citizens is restricted as hardly any physical process exists that leads to a local reduction of moisture [11], which itself is governed by the large-scale weather conditions. Provided that it is not too low, the ventilation of cities has the potential to reduce the heat stress perceived by citizens. Therefore, all planning methods to mitigate heat stress on the urban scale should also include an improvement of the local ventilation conditions [12].

To cope with the need for action, urban planning needs quantitative fundamentals of urban human-biometeorology. For that purpose, results of investigations can be applied, which provide indications on the variation of human thermal comfort caused by changed urban design parameters [2, 13-15]. These investigations show a common feature: thermophysiological assessment indices are used, which were derived from the human heat budget. The physiologically equivalent temperature PET defined by Mayer and Höppe [16] represents one of those indices. Compared to similar indices, it has the advantage that many results for PET are available in the meantime, which has been obtained by numeric simulations or experiments worldwide [17-22]. They facilitate the comparative evaluation of thermal stress conditions for citizens. It will take some time, until the recently developed universal thermal climate index UTCI [23] reaches a similar basis of comparison. In addition, the current version of UTCI does not include a new approach to determine the mean radiant temperature $T_{\text {mrt }}$ but recommends the use of existing simulation tools like the RayMan model [24].

In Central Europe, severe heat occurs only in summer, when day is longer than night. Therefore, urban planning prefers a double strategy for methods aiming at maintaining thermal comfort for citizens under severe heat. Methods, which are effective in the daytime, have a first priority, while methods, which are related only to nocturnal meteorological phenomena like thermally induced down-slope or mountain air flow, are often classified as secondary. The general objective of planning methods for the daytime conditions is to reduce the heat input into all urban spaces. This should be achieved in compliance with the targets of environmental protection, that is, avoidance of air conditioning systems. According to results of investigations on outdoor thermal comfort conducted in inland cities during clear-sky weather $[2,13-15,18,22,25]$, the radiant exchange is the dominant meteorological factor affecting thermal comfort in the daytime. Therefore, the decrease of the direct solar radiation by shading can be the most effective method to reduce the heat entered into urban spaces $[2,13,15,25-31]$. Transpiration from vegetation leads to a lowering of its surface temperature [32] including a slight decrease of $T_{a}$ above the vegetation layer, but this effect does not reach a comparative magnitude of shading impacts on citizens.

Local shading of direct solar radiation within the urban canopy layer can be achieved by (i) optimized design of buildings, open spaces, and streets $[2,14,15]$, (ii) man-made devices like awnings or sunshades, and (iii) street trees [2, 13, 25-31]. Under a human-biometeorological point of view, which includes aesthetic and psychological aspects, shading by street trees has the highest significance despite conflicting goals like impacts on the near-surface air flow or emission of BVOC as a precursor for the ozone formation [10].

The radiant exchange, which is relevant to the perception of heat by citizens $[1,25]$, can be quantified by $T_{\text {mrt }}$. It represents a measure for the heat of the short- and long-wave radiant flux densities from the three-dimensional environment absorbed by the human-biometeorological reference person and plays a fundamental role in the thermophysiological concept to assess the thermal environment $[1,2,33]$.

In order to get a deeper understanding on the physical processes, which lead to a local reduction of heat for citizens, the main objective of this study is to quantify the humanbiometeorological consequences of two effective shading methods, namely, shading by (i) a building and (ii) street trees. Against the background of existing studies on humanbiometeorological shading effects, this study is focussed on the pattern of measured three-dimensional short- and longwave radiant flux densities, which will be analyzed in a comparative way for both shading devices. This approach enables a physically based explanation of the spatiotemporal behaviour of $T_{\text {mrt }}$ in contrast to $T_{a}$. Up to now, it is only available to some extent. As for inland cities in Central Europe, the daytime values of PET on typical summer days are strongly influenced by $T_{\mathrm{mrt}}[2,13]$, the daytime pattern of PET can be interpreted by $T_{\mathrm{mrt}}$. The analysis of the threedimensional radiant fields should also give hints on the potential to manipulate physical surface properties aimed at an additional lowering of radiant flux densities from selected directions.

\section{Materials and Methods}

On typical Central European summer days during the period 2007-2010, several 1-day human-biometeorological measuring campaigns were conducted in different quarters of Freiburg (Southwest Germany) within the scope of the KLIMES project [1]. Their main objective has been the quantitative analysis of the influences of street design characteristics on those meteorological variables, which are necessary to calculate PET, that is, particularly $T_{a}$ and $T_{\mathrm{mrt}}$. In order to get a better insight into the pattern of radiant flux densities as well as $T_{\text {mrt }}$ and PET during shading situations, two measuring campaigns were selected for this specific issue (Figure 1), one on July 15, 2007, and another on July 24, 2008. They were performed within the same WNW-ESE street canyon in the "Vauban" quarter but at different sites (Figure 1), which were about $300 \mathrm{~m}$ off each other. During each measuring campaign, parallel human-biometeorological measurements were conducted at a sunny and a shaded measuring site. As the weather conditions on both summer days were quite similar, the requirements for a comparison of the results, which can be regarded as representative for both shading situations, were met.

The specific objective of the measuring campaign on July 15, 2007, was the human-biometeorological analysis of shading of the direct solar radiation caused by a three-storey building (height: $15 \mathrm{~m}$ ). The main measuring site was at 


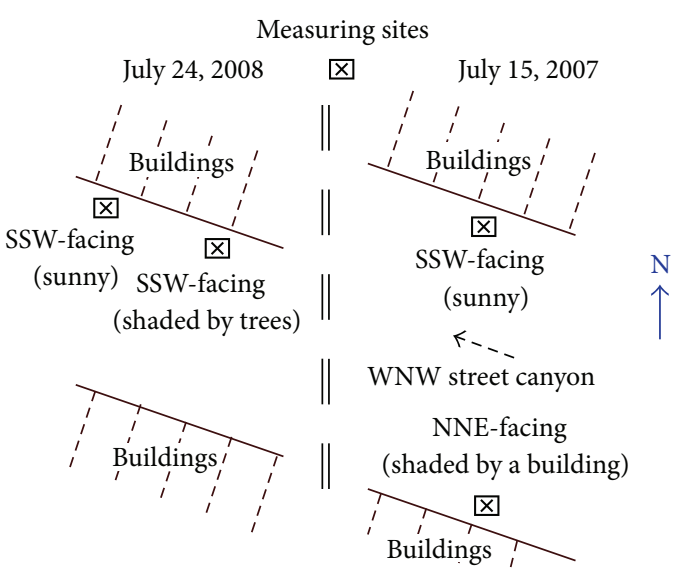

(a)

(b)

FIGURE 1: Location of the measuring sites during the humanbiometeorological measuring campaigns within the same WNW street canyon in the "Vauban" quarter of Freiburg conducted on typical Central European summer days on July 15, 2007 (b) and July 24, 2008 (a).

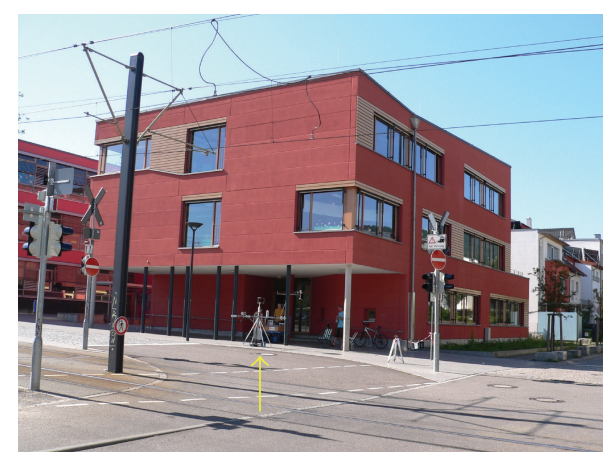

FIgURE 2: Human-biometeorological measuring site at the NNEfacing sidewalk of a WNW street canyon in Freiburg, "Vauban" quarter, July 15, 2007.

the NNE-facing sidewalk about $1 \mathrm{~m}$ apart in front of this building (Figure 2). The site of comparison was at the opposite SSW-facing sidewalk in a distance of about $60 \mathrm{~m}$.

The experimental investigation on July 24, 2008, addressed the human-biometeorological consequences of shading of the direct solar radiation by the canopy of five small leaved linden trees (Figure 3). They were planted about $10 \mathrm{~m}$ apart from a four-storey SSW-facing building, arranged parallel to the street axis, and spaced about $8 \mathrm{~m}$ apart from trunk to trunk of each tree. The main measuring site was at the sidewalk about $2.5 \mathrm{~m}$ apart in front of the building and about $7.5 \mathrm{~m}$ far from the stem of the centered small leaved linden tree. The individual tree height and crown diameter were about $25 \mathrm{~m}$ and $10 \mathrm{~m}$, respectively. In the light of these, this site was almost shaded during the entire summer days. The site for a comparison was located in a distance of about $40 \mathrm{~m}$ at the same SSW-facing sidewalk about $2.5 \mathrm{~m}$ apart in front of another four-storey building but not influenced by trees.
TABLE 1: Aspect ratio $H / W$ ( $H$ : building height, $W$ : street width) and $\mathrm{SVF}_{90-270}$ (sky view factor related to the southern half of the upper hemisphere) at the measuring sites within the WNW street canyon in Freiburg, "Vauban" quarter.

\begin{tabular}{lcccc}
\hline & \multicolumn{2}{c}{ July 15, 2007} & \multicolumn{2}{c}{ July 24, 2008 } \\
$\begin{array}{c}\text { NNE-facing, } \\
\text { shaded }\end{array}$ & $\begin{array}{c}\text { SSW-facing, } \\
\text { sunny }\end{array}$ & $\begin{array}{c}\text { SSW-facing, } \\
\text { sunny }\end{array}$ & $\begin{array}{c}\text { SSW-facing, } \\
\text { shaded }\end{array}$ \\
\hline$H / W$ & 0.25 & 0.25 & 0.39 & 0.39 \\
SVF $_{90-270}$ & $20 \%$ & $65 \%$ & $70 \%$ & $6 \%$ \\
\hline
\end{tabular}

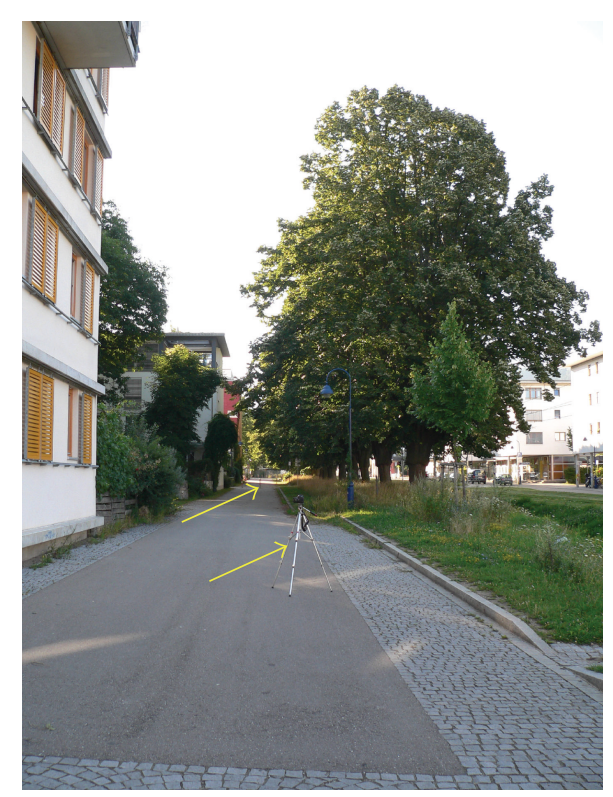

FIGURE 3: Human-biometeorological measuring sites at the sunny (in the front) and shaded (at the back) SSW-facing sidewalk of a WNW street canyon in Freiburg, "Vauban" quarter, July 24, 2008.

To characterize the measuring sites, Table 1 contains their sky view factors $\mathrm{SVF}_{90-270}$ related to the southern half of the upper hemisphere, that is, from east via south to west, and the aspect ratios $H / W$ of the street canyon. According to [2, 13], $\mathrm{SVF}_{90-270}$ is more suitable for human-biometeorological investigations on thermal comfort in contrast to SVF for the complete upper hemisphere, because $\mathrm{SVF}_{90-270}$ is closely related to the direct solar radiation (Figure 4).

For the measurements, a specific human-biometeorological device was used, which consists of a stationary station (Figure 5) and a mobile station. Both are described in detail in $[1,2]$. They measure all meteorological variables in the human-biometeorological reference height of $1.1 \mathrm{~m}$ that are necessary to calculate $T_{\text {mrt }}$ and PET. For PET, the method was applied, which is described in detail in $[1,2,13,33]$.

To determine $T_{\mathrm{mrt}}$, the approach by Höppe [34] was used. It required the measurement of the short- and long-wave radiant flux densities received by the human-meteorological reference person from the three-dimensional environment. For that purpose, the setup of the station in Figure 5 contains three cantilevers. A pair of two pyranometers and two pyrgeometers was attached to each of the three cantilevers 




(a)

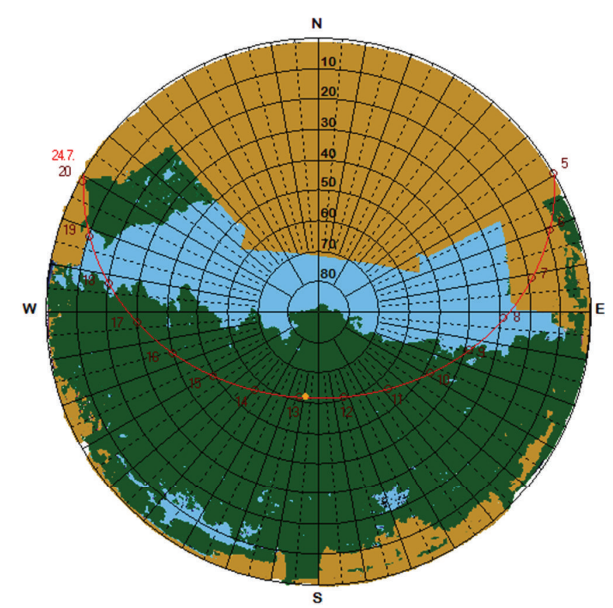

(b)

FIGURE 4: Fish-eye photos from the upper hemisphere at the sunny (a) and shaded (b) site during the human-biometeorological measuring campaign in Freiburg on July 24, 2008 [2, 13].

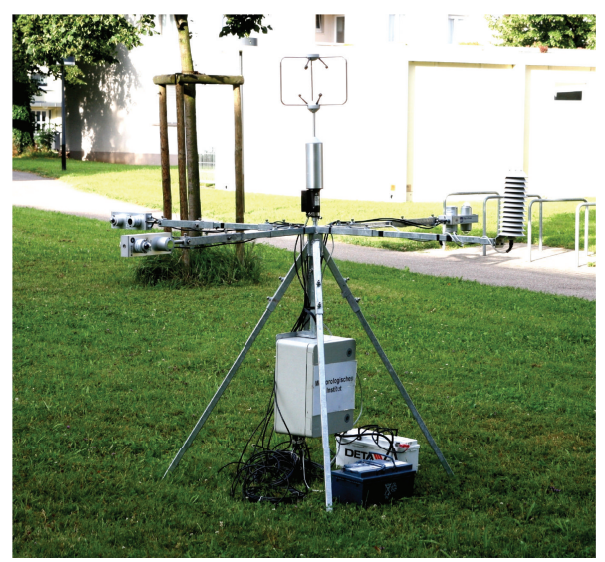

FIGURE 5: Stationary human-biometeorological station for experimental investigations to determine $T_{\text {mrt }}$ and PET within urban structures in Freiburg.

in order to enable the parallel measurement of the two vertical and four horizontal short- and long-wave radiant flux densities. Similar measuring systems have proven to be successful in human-biometeorological investigations, which were conducted in Gothenburg, Sweden, [35], Szeged, Hungary, [36] and Lisbon, Portugal [37]. Based on this method, $T_{\mathrm{mrt}}$ (in ${ }^{\circ} \mathrm{C}$ ) was calculated according to the Stefan-Boltzmann law by

$$
T_{\mathrm{mrt}}=\sqrt[4]{\frac{K_{\mathrm{abs}}^{*}+L_{\mathrm{abs}}^{*}}{\varepsilon_{p} \cdot \sigma}}-273.15,
$$

where $K_{\mathrm{abs}}^{*}$ is the sum of short-wave radiant flux densities from the three-dimensional environment absorbed by the human-biometeorological reference person, $L_{\mathrm{abs}}^{*}$ is the sum of long-wave radiant flux densities from the threedimensional environment absorbed by the human-biometeorological reference person, $\varepsilon_{p}$ is its long-wave emissivity, and $\sigma$ is the Stefan-Boltzmann constant.
$K_{\text {abs }}^{*}$ was determined by [34]

$$
K_{\mathrm{abs}}^{*}=\alpha_{k} \cdot \sum_{i=1}^{6} W_{i} \cdot K_{i},
$$

where $\alpha_{k}$ is the absorption coefficient of the reference person for the short-wave radiation, $W_{i}$ are the weighting factors of the standing reference person for the three-dimensional radiant flux densities $K_{i}(i=$ downward, upward, E, S, W, N); that is, $W$ is 0.06 for the vertical and 0.22 for the horizontal radiant flux densities.

In the same way $L_{\mathrm{abs}}^{*}$ was calculated by

$$
L_{\mathrm{abs}}^{*}=\alpha_{l} \cdot \sum_{i=1}^{6} W_{i} \cdot L_{i},
$$

where $\alpha_{l}$ is the absorption coefficient of the reference person for the long-wave radiation.

Compared to a globe thermometer, which also enables the determination of $T_{\text {mrt }}[35,38]$, the set-up used in this study has two advantages, which are of importance for the discussion of urban planning methods against heat: (i) the differentiation between the effects of all short- and long-wave radiant flux densities is possible, and (ii) a differentiation of the radiant flux densities according to their spatial directions can be made.

For practical applications of PET like in urban planning, it is advisable to classify the PET values in terms of the ASHRAE thermal sensation scale, which represents a kind of standard. Based on results of suitable questionnaires for citizens and parallel experiments to determine PET, the PET classification scheme achieved for summer conditions in Freiburg [13] is shown in Table 2. This method, which was also applied in another investigations like in Gothenburg, Sweden, [39], Lisbon, Portugal, [37], Szeged, Hungary, [40], Taichung City, Taiwan [41], and Hong Kong [42], considers the acclimatization and adaptation of citizens to the local thermal environment. 
TABLE 2: Ranges of the physiologically equivalent temperature PET for different warm levels of human thermal sensation according to the ASHRAE thermal sensation scale determined for summer conditions in Freiburg [13].

\begin{tabular}{lcc}
\hline \multicolumn{2}{c}{ ASRAE thermal sensation scale } & PET range $\left({ }^{\circ} \mathrm{C}\right)$ \\
Name & Scale & \\
\hline Slightly warm & +1 & $30-34$ \\
Warm & +2 & $35-40$ \\
Hot & +3 & $>40$ \\
\hline
\end{tabular}

Both are not included in the well-known classification scheme of PET by [43], as it has been developed from comparative numeric calculations of PMV and PET for different weather stations in Greece covering the period 1990-1999. Based on a linear regression analysis, the PMV thresholds according to [44] for different human thermal sensations were transferred into corresponding PET thresholds.

This method has two weaknesses. (i) Basically, the original PMV thresholds were only developed for indoor climate; that is, simplified approaches for the human heat budget as basis for PMV were used. They are only valid for slight deviations from the human thermal comfort. Due to the meteorological conditions in Greece, the deviations from the thermal comfort are much stronger at least in summer. Therefore, PMV should not be applied to outdoor conditions like in Greece. (ii) The PET classification scheme by [43] is not generally applicable because it is limited to an internal human heat production of $80 \mathrm{~W}$ and a heat transfer resistance of human clothing of 0.9 clo.

\section{Results and Discussion}

3.1. Shading by a Building. According to $[2,13]$, the results of the measuring campaign on July 15,2007 , show that the shading effect was only reflected by $T_{\text {mrt }}$ and PET but hardly by $T_{a}$ (Figure 6). It occurred from 10-16 CET and was caused by the building, which was located about $1 \mathrm{~m}$ apart in opposite direction to the NNE-facing measuring site. The shading led to a reduction of $T_{\text {mrt }}$ by about $18^{\circ} \mathrm{C}$ and of PET by about $7^{\circ} \mathrm{C}$. PET exceeded the thermophysiological threshold value under hot conditions in Freiburg (Table 2) only from 16-18 CET.

With respect to the strong $T_{\text {mrt }}$ dependence of daytime PET in Central European cities in summer [2, 13], differentiated analyses of the short- and long-wave radiant flux densities give a deeper insight into their behaviour, which is relevant to $T_{\mathrm{mrt}}$. In contrast to other studies [1], Figure 7 does not contain absolute values of the direction-dependent shortwave radiant flux densities $K_{i}(i=$ down, up, E, S, W, and N) but normalized values related to the daily $1 \mathrm{~h}$ peak value of the short-wave radiant flux density from the upper hemisphere $\left(K_{\text {down,max }}\right)$. Thus, results from different measuring campaigns can be easily compared. The results of $K_{i} / K_{\text {down,max }}$ show that the shading by the building led to relative $K_{i}$ values below $10 \%$. The geometry of the measuring site caused the strongest drop for $K_{\text {down }}, K_{\mathrm{E}}$, and $K_{\mathrm{W}}$.

Due to the standing position of the human-biometeorological reference person, which results in different weighting

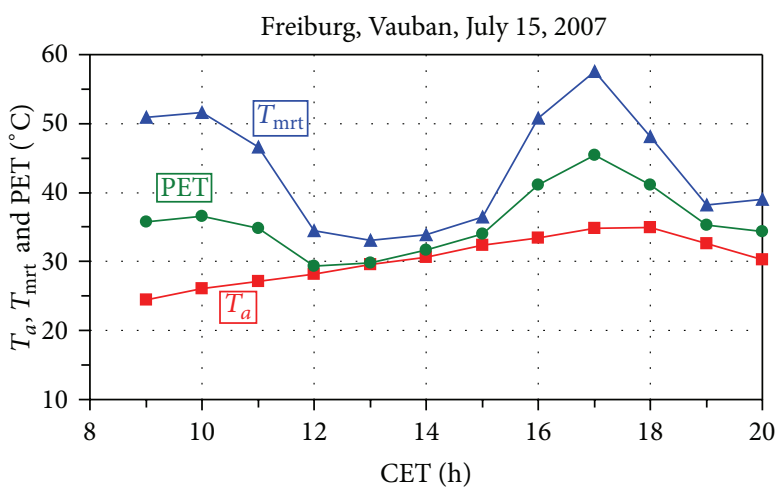

FIgURE 6: $1 \mathrm{~h}$ mean values of air temperature $T_{a}$, mean radiant temperature $T_{\mathrm{mrt}}$, and physiologically equivalent temperature PET at the NNE-facing sidewalk of a WNW-ESE street canyon, "Vauban" quarter in Freiburg during typical Central European summer day.



FIGURE 7: $1 \mathrm{~h}$ mean values of the short-wave radiant flux densities $K_{i}(i=$ down, up, E, $\mathrm{S}, \mathrm{W}$, and $\mathrm{N})$ reaching the human-biometeorological reference person from the three-dimensional environment, related to the daily $1 \mathrm{~h}$ peak value of $K_{\text {down }}\left(K_{\text {down,max }}=659 \mathrm{~W} / \mathrm{m}^{2}\right)$, NNE-facing sidewalk of a WNW-ESE street canyon, "Vauban" quarter in Freiburg during typical Central European summer day.

factors with respect to the radiant flux densities $[2,16,33$, 34 , and its absorption coefficient (0.7) for $K_{i}$, the amounts of $K_{i, \text { abs }}$, that is, short-wave radiant flux densities from the three-dimensional environment absorbed by the humanbiometeorological reference person, were lower (Figure 8) compared to $K_{i}$, in particular for $K_{\text {down,abs }}$ and $K_{\text {up,abs }}[1]$. The shading by the building led to relative $K_{i, \text { abs }}$ values, which were about $7 \%$ for $K_{\text {down,abs }}, 1 \%$ for $K_{\text {up,abs }}, 25 \%$ for $K_{\mathrm{E}, a b s}, 30 \%$ for $K_{\mathrm{S}, \mathrm{abs}}, 18 \%$ for $K_{\mathrm{W}, \mathrm{abs}}$, and $7 \%$ for $K_{\mathrm{N}, \mathrm{abs}}$.

The response of the direction-dependent long-wave radiant flux densities $L_{i}$ on the shading by the building (Figure 9) turned out to be distinctly weaker as compared to $K_{i}$. With the exception of $L_{\text {down }}$, that is, the long-wave radiant flux density from the upper hemisphere, the shading caused a drop of about $10 \%$ of the relative $L_{i}$ values, which were related to the $1 \mathrm{~h}$ peak value of $L_{\text {up }}$, that is, long-wave radiant flux density from the lower hemisphere. It is noticeable that the $L_{\text {down }}$ values were about $15 \%$ lower than the other $L_{i}$ values, whose behaviour and range were quite similar. 


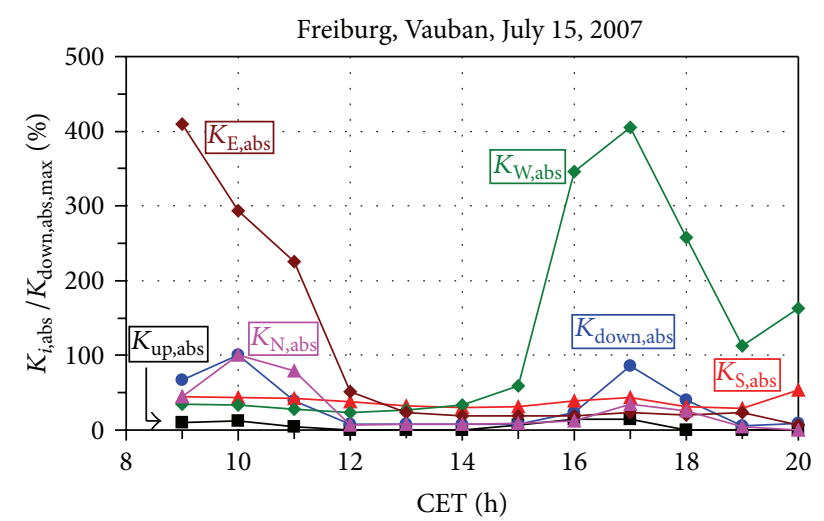

FIgURE 8: $1 \mathrm{~h}$ mean values of the short-wave radiant flux densities $K_{i, \text { abs }}(i=$ down, up, E, S, W, and $\mathrm{N}$ ) from the three-dimensional environment absorbed by the human-biometeorological reference person, related to the $1 \mathrm{~h}$ peak value of $K_{\text {down,abs }}\left(K_{\text {down,abs,max }}=\right.$ $28 \mathrm{~W} / \mathrm{m}^{2}$ ), NNE-facing sidewalk of a WNW-ESE street canyon, "Vauban" quarter in Freiburg during typical Central European summer day.



FIGURE 9: $1 \mathrm{~h}$ mean values of the long-wave radiant flux densities $L_{i}$ ( $i$ = down, up, E, $\mathrm{S}, \mathrm{W}$, and $\mathrm{N}$ ) reaching the human-biometeorological reference person from the three-dimensional environment, related to the $1 \mathrm{~h}$ peak value of $L_{\text {up }}\left(L_{\text {up, } \max }=533 \mathrm{~W} / \mathrm{m}^{2}\right)$, NNEfacing sidewalk of a WNW-ESE street canyon, "Vauban" quarter in Freiburg during typical Central European summer day.

With respect to the long-wave radiant flux densities $L_{i, \text { abs }}$ from the three-dimensional environment absorbed by the human-biometeorological reference person, its absorption coefficient $(0.97)$ for $L_{i}$ led to a slight lowering of $L_{i, \text { abs }}$. In addition, a more pronounced reduction of $L_{i, \text { abs }}$ was caused by the weighting factors for radiant flux densities due to the standing position of the reference person (Figure 10). Due to the selected reference ( $1 \mathrm{~h}$ peak value of $L_{\text {up,abs }}$ ), the vertical radiant flux densities $L_{\text {down,abs }}$ and $L_{\text {up,abs }}$ were at least $200 \%$ lower than the horizontal $L_{i \text {,abs }}$ values, whereby $L_{\text {up,abs }}$ was by $13 \%$ higher than $L_{\text {down,abs }}$. The values of the four horizontal $L_{i, \text { abs }}(i=\mathrm{E}, \mathrm{S}, \mathrm{W}$, and $\mathrm{N})$ were quite similar in their range and scattered around $330 \%$ on average. Interestingly, the reference values $K_{\text {down,abs, } \max }\left(28 \mathrm{~W} / \mathrm{m}^{2}\right)$ and $L_{\text {up,abs,max }}\left(31 \mathrm{~W} / \mathrm{m}^{2}\right)$ were in a similar range.

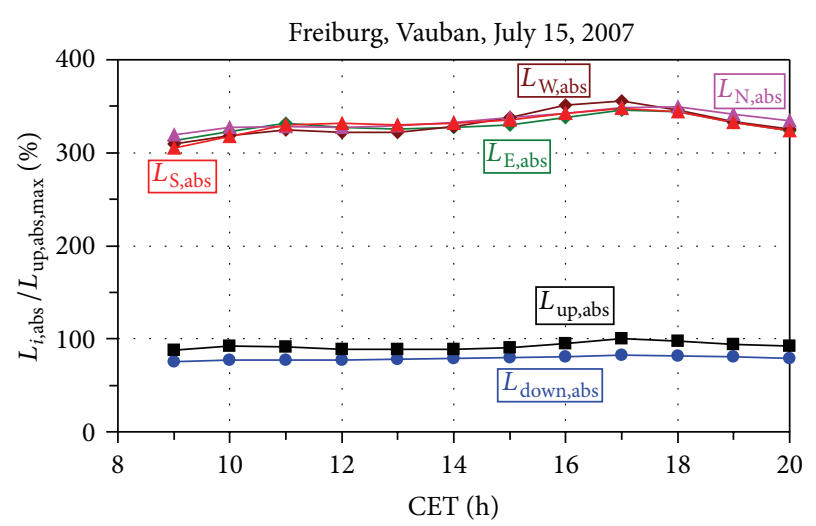

FIGURE 10: $1 \mathrm{~h}$ mean values of the long-wave radiant flux densities $L_{i \text {,abs }}(i=$ down, up, E, S, W, and $\mathrm{N}$ ) from the three-dimensional environment absorbed by the human-biometeorological reference person, related to the $1 \mathrm{~h}$ peak value of $L_{\text {up,abs }}\left(L_{\text {up,abs,max }}=31 \mathrm{~W} / \mathrm{m}^{2}\right)$, NNE-facing sidewalk of a WNW-ESE street canyon, "Vauban" quarter in Freiburg during typical Central European summer day.



Figure 11: $1 \mathrm{~h}$ mean values of differences $\Delta$ of air temperature $T_{a}$, mean radiant temperature $T_{\mathrm{mrt}}$, and physiologically equivalent temperature PET between the shaded NNE- and sunny SSWfacing sidewalk of a WNW-ESE street canyon, "Vauban" quarter in Freiburg during typical Central European summer day.

In order to assess the effectiveness of the shading by a building, the differences $\Delta$ of $T_{a}, T_{\mathrm{mrt}}$, and PET between the shaded NNE- and sunny SSW-facing sidewalk were determined (Figure 11). The peak values of $\Delta T_{a}, \Delta T_{\mathrm{mrt}}$, and $\Delta \mathrm{PET}$ were $-1.7^{\circ} \mathrm{C},-29.0^{\circ} \mathrm{C}$, and $-13.1^{\circ} \mathrm{C}$, respectively; that is, $\Delta T_{\text {mrt }}$ strongly reacted on the shading as it mainly affected the radiant exchange. The findings of similar investigations $[1,2$, $13,22,24]$ that $T_{\text {mrt }}$ turns out to be a key variable for PET during typical Central European summer weather can be confirmed by Figure 11. Therefore, the peak value of $\triangle \mathrm{PET}$ was comparatively high. It corresponded to a mitigation of the human thermal sensation from "hot" to "slightly warm" according to the ASHRAE scale. Due to the physical processes that govern the heat exchange in the near-surface layer, the resulting variable $T_{a}$, which represents the sensible heat conditions, only showed a slight effect of the shading. As the human-biometeorological concept to assess the human perception of heat is not only related to the sensible heat, 


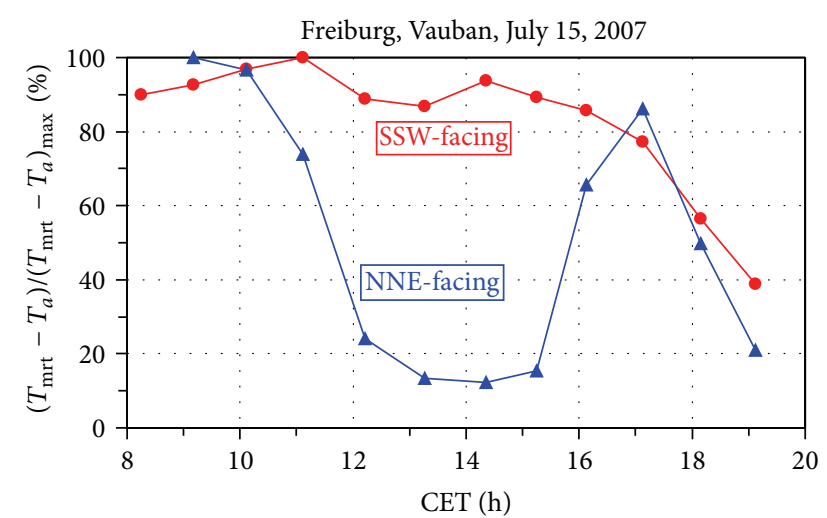

FIGURE 12: $1 \mathrm{~h}$ mean values of the difference between mean radiant temperature $T_{\mathrm{mrt}}$ and air temperature $T_{a}$, related to the $1 \mathrm{~h}$ peak value of $\left(T_{\mathrm{mrt}}-T_{a}\right)$ at the shaded NNE-facing sidewalk $\left(\left(T_{\mathrm{mrt}}-T_{a}\right)_{\max }=\right.$ $\left.26.4^{\circ} \mathrm{C}\right)$ and sunny SSW-facing sidewalk $\left(\left(T_{\operatorname{mrt}}-T_{a}\right)_{\max }=33.3^{\circ} \mathrm{C}\right)$ of a WNW-ESE street canyon, "Vauban" quarter in Freiburg during typical Central European summer day.

$T_{a}$ or the urban heat island intensity $\mathrm{UHI}$ is inappropriate to characterize the human thermal sensation [13-15].

At the sunny SSW-facing sidewalk, the peak difference between $T_{\text {mrt }}$ and $T_{a}$ was relatively high $\left(33.3^{\circ} \mathrm{C}\right.$ at $\left.11 \mathrm{CET}\right)$, while shading by the building reduced $\left(T_{\mathrm{mrt}}-T_{a}\right)$ up to $3.2^{\circ} \mathrm{C}$ (14 CET) at the NNE-facing sidewalk. For the normalized $\left(T_{\mathrm{mrt}}-T_{a}\right)$, it corresponds about $12 \%$ (Figure 12 ), whereas the normalized $\left(T_{\mathrm{mrt}}-T_{a}\right)$ was higher than $80 \%$ at the sunny sidewalk during 10-16 CET, which can be regarded as the period with the strongest heat for citizens.

The difference $\Delta$ of the sums of the short-wave radiant flux densities $\left(K_{\mathrm{abs}}^{*}\right)$ from the three-dimensional environment absorbed by the human-biometeorological reference person between the shaded NNE- and sunny SSW-facing sidewalk was higher (Figure 13) than those of the sums of the longwave radiant flux densities $\left(L_{\mathrm{abs}}^{*}\right)$. For $\Delta K_{\mathrm{abs}}^{*}$, the difference was the strongest $\left(-171 \mathrm{~W} / \mathrm{m}^{2}\right)$ around 14 CET, while the peak value of $\Delta L_{\mathrm{abs}}^{*}$ amounted to $-43 \mathrm{~W} / \mathrm{m}^{2}$ around $13 \mathrm{CET}$. From this it follows that shading by a building causes a stronger impact on $K_{\mathrm{abs}}^{*}$ than on $L_{\mathrm{abs}}^{*}$. Therefore, the differences of $T_{\mathrm{mrt}}$ between the sunny and the shaded sidewalk of the street canyon were mainly caused by $\Delta K_{\mathrm{abs}}^{*}$.

The magnitude of $T_{\mathrm{mrt}}$ is governed by the values of $K_{\mathrm{abs}}^{*}$ and $L_{\mathrm{abs}}^{*}$. Referred to $\left(K_{\mathrm{abs}}^{*}+L_{\mathrm{abs}}^{*}\right)$, the relative $K_{\mathrm{abs}}^{*}$ for the sunny SSW-facing sidewalk did not exceed 30\% (Figure 14), while it reached $6 \%$ at the shaded NNE-facing sidewalk. This implies that the relative $L_{\text {abs }}^{*}$ comprised about $70 \%$ for the case of the sunny (see also [1]) and about $94 \%$ in the shaded situation. Consequently, shading not only reduces the threedimensional radiant flux densities and, therefore, $T_{\text {mrt }}$ but also leads to a higher portion of relative $L_{\mathrm{abs}}^{*}$ for $T_{\mathrm{mrt}}$ than in the sunny situation.

3.2. Shading by Tree Canopies. The shading effect by tree canopies, which was investigated in the measuring campaign conducted on July 24, 2008, in the same street canyon, started about $10 \mathrm{CET}$ and lasted the entire day (Figures 4 and 15).

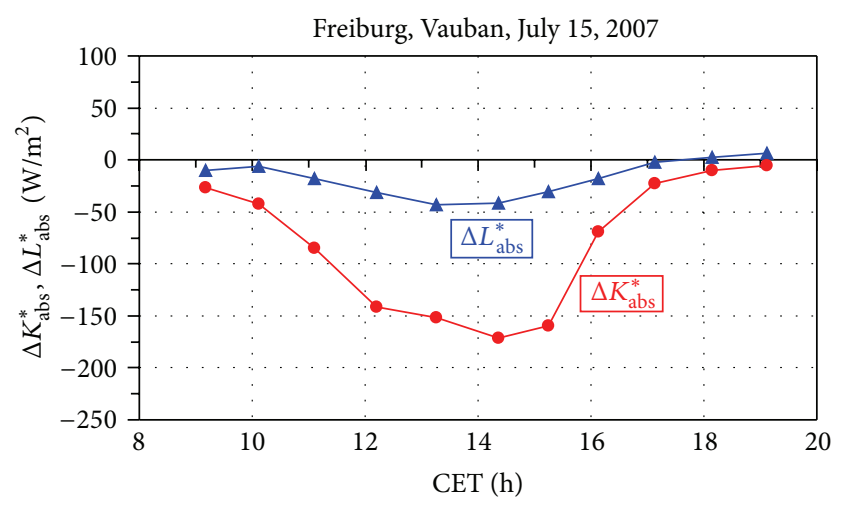

FIGURE 13: $1 \mathrm{~h}$ mean values of differences $\Delta$ of the sums of shortwave radiant flux densities $\left(K_{\mathrm{abs}}^{*}\right)$ and long-wave radiant flux densities $\left(L_{\text {abs }}^{*}\right)$ from the three-dimensional environment absorbed by the human-biometeorological reference person between the shaded NNE- and sunny SSW-facing sidewalk of a WNW-ESE street canyon, "Vauban" quarter in Freiburg during typical Central European summer day.

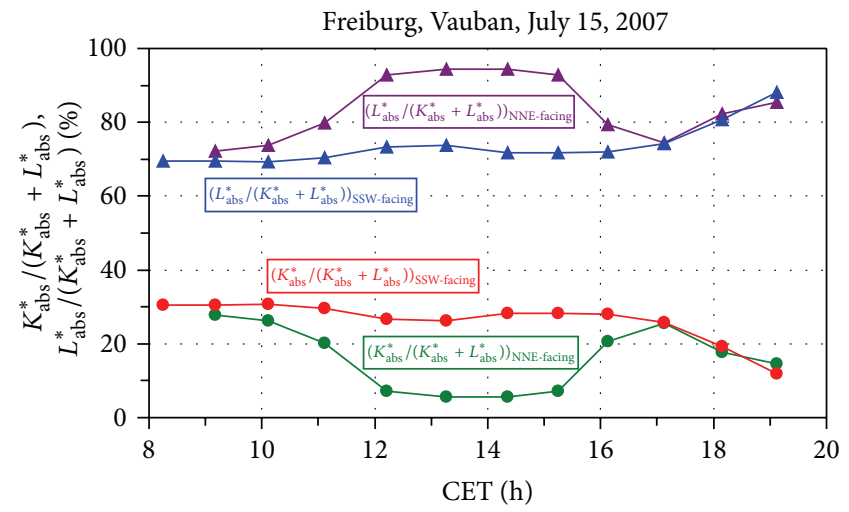

FIGURE 14: $1 \mathrm{~h}$ mean values of the sums of short-wave radiant flux densities $\left(K_{\mathrm{abs}}^{*}\right)$ and long-wave radiant flux densities $\left(L_{\mathrm{abs}}^{*}\right)$ from the three-dimensional environment absorbed by the humanbiometeorological reference person, related to $1 \mathrm{~h}$ mean values of $\left(K_{\mathrm{abs}}^{*}+L_{\mathrm{abs}}^{*}\right)$, at the shaded NNE- and sunny SSW-facing sidewalk of a WNW-ESE street canyon, "Vauban" quarter in Freiburg during typical Central European summer day.

As reflected by the results of both shading cases (Figures 6 and 15), $T_{a}$ and PET were in a similar range, while $T_{\text {mrt }}$ was about $5^{\circ} \mathrm{C}$ higher than $T_{a}$. According to the PET classification for Freiburg (Table 2), the PET values did not indicate any kind of thermal load.

The relative short-wave radiant flux densities hardly differentiated between both shading cases (Figures 7 and 16) with the exception that the shading by tree canopies extended over a longer time period; that is, $K_{\mathrm{W}}$ was also comparatively low in the afternoon. Due to the transmission of the shortwave radiation through the canopy [45], the relative $K_{\text {down }}$ values for the case of the tree shading were about $4 \%$ higher than those for the shading through the building.

As for shading by a building, the relative $K_{i \text {,abs }}$ values at the measuring site shaded by tree canopies (Figure 17) also 


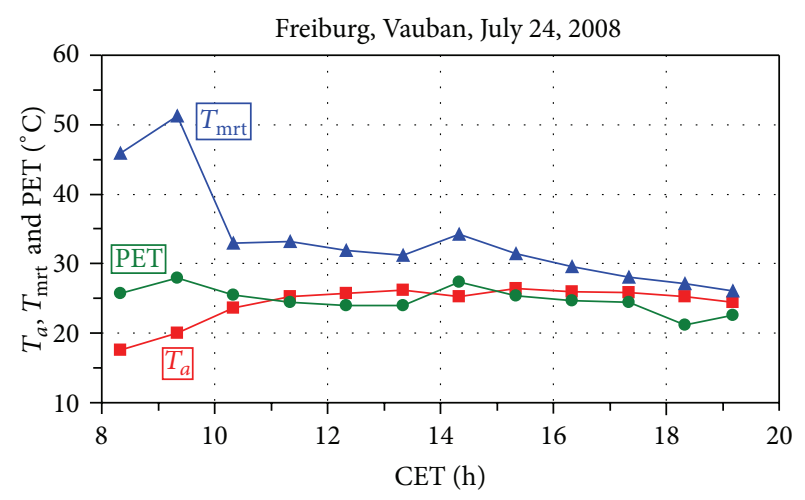

FIGURE 15: $1 \mathrm{~h}$ mean values of air temperature $T_{a}$, mean radiant temperature $T_{\mathrm{mrt}}$, and physiologically equivalent temperature PET, SSW-facing sidewalk (shaded by tree canopies) of a WNW-ESE street canyon, "Vauban" quarter in Freiburg during typical Central European summer day.

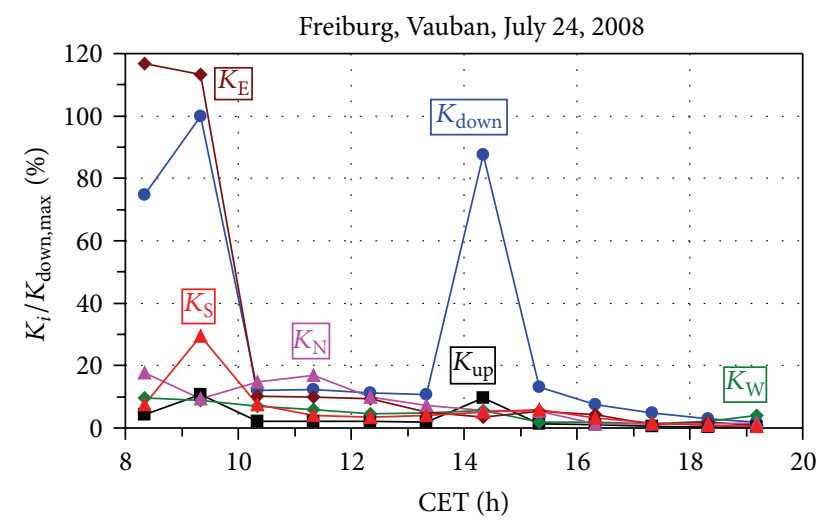

FIGURE 16: $1 \mathrm{~h}$ mean values of the short-wave radiant flux densities $K_{i}(i=$ down, up, E, $\mathrm{S}, \mathrm{W}$, and $\mathrm{N})$ reaching the humanbiometeorological reference person from the three-dimensional environment, related to the $1 \mathrm{~h}$ peak value of $K_{\text {down }}\left(K_{\text {down, max }}=\right.$ $600 \mathrm{~W} / \mathrm{m}^{2}$ ), SSW-facing sidewalk (shaded by tree canopies) of a WNW-ESE street canyon, "Vauban" quarter in Freiburg during typical Central European summer day.

reflected the short-wave radiation exchange, which is relevant to the calculation of $T_{\mathrm{mrt}}$ and was predetermined by the relative $K_{i}$ values (Figure 16). The longer duration of the shading effect at the measuring site under the tree canopies was responsible for the comparatively low $K_{i \text { abs }}$ values in the afternoon. With the exception of the relative $K_{\text {down,abs }}$ at about $14 \mathrm{CET}$, the relative $K_{i, \text { abs }}$ values in the afternoon were below $20 \%$ and showed a lower direction-dependent variability compared to the shading in the late morning. Around noon, the shading by tree canopies led to relative $K_{i, \text { abs }}$ values up to $11 \%$ for $K_{\text {down,abs }}, 2 \%$ for $K_{\text {up,abs }}, 18 \%$ for $K_{\mathrm{E}, \mathrm{abs}}, 13 \%$ for $K_{\mathrm{S}, \mathrm{abs}}$, $17 \%$ for $K_{\mathrm{W}, \mathrm{abs}}$, and $27 \%$ for $K_{\mathrm{N}, \mathrm{abs}}$.

In contrast to Figure 9 , where $L_{\text {down }} / L_{\text {up, max }}$ was continuously lower by at least $10 \%$ than the other relative $L_{i}$ values, the temporal course of $L_{\text {down }} / L_{\text {up,max }}$ (Figure 18) was more pronounced and almost touched the other relative $L_{i}$ values around $14 \mathrm{CET}$. As the shading by a building referred



FIGURE 17: $1 \mathrm{~h}$ mean values of the short-wave radiant flux densities $K_{i \text {,abs }}(i=$ down, up, E, S, W, and $\mathrm{N}$ ) from the three-dimensional environment absorbed by the human-biometeorological reference person, related to the $1 \mathrm{~h}$ peak value of $K_{\text {down,abs }}\left(K_{\text {down,abs,max }}=\right.$ $25 \mathrm{~W} / \mathrm{m}^{2}$ ), SSW-facing sidewalk (shaded by tree canopies) of a WNW-ESE street canyon, "Vauban" quarter in Freiburg during typical Central European summer day.

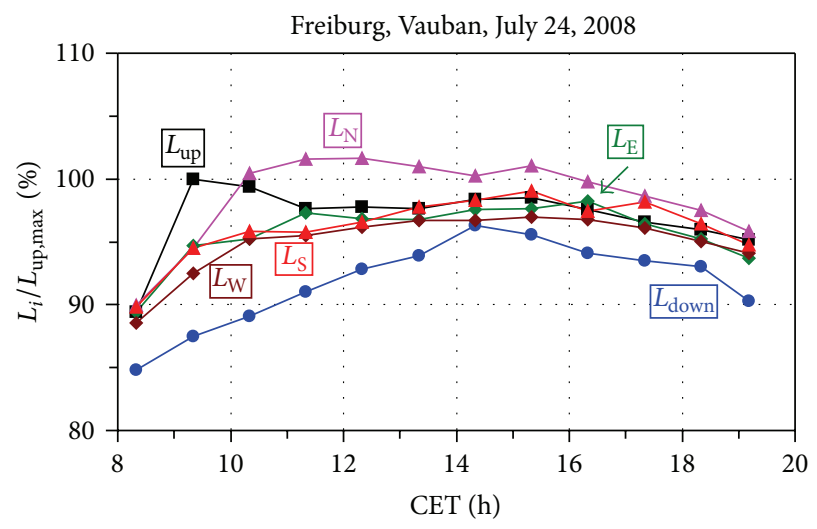

FIGURE 18: $1 \mathrm{~h}$ mean values of the long-wave radiant flux densities $L_{i}(i=$ down, up, E, S, W, and $\mathrm{N})$ reaching the humanbiometeorological reference person from the three-dimensional environment, related to the $1 \mathrm{~h}$ peak value of $L_{\text {up }}\left(L_{\text {up, max }}=\right.$ $474 \mathrm{~W} / \mathrm{m}^{2}$ ), SSW-facing sidewalk (shaded by tree canopies) of a WNW-ESE street canyon, "Vauban" quarter in Freiburg during typical Central European summer day.

to about 4 hours around noon, the $1 \mathrm{~h}$ peak value of $L_{\text {up }}$ occurred in the late afternoon (Figure 9), which caused some kind of a diurnal variation of the relative $L_{i}$ values. As the shading by tree canopies extended over the entire afternoon, the $1 \mathrm{~h}$ peak value of $L_{\text {up }}$ was already observed in the early morning (Figure 18). Due to the following shading at the measuring site, the temporal courses of the relative $L_{i}$ values, with the exception of $L_{\text {down }}$, scattered around a near-constant level until the late afternoon. The specific location of the measuring site, that is, about $2.5 \mathrm{~m}$ apart in front of a SSWfacing building, was mainly responsible for the relative values of $L_{\mathrm{N}}$, which were slightly above $100 \%$.

Also for the shading by tree canopies, the relative $L_{\text {up,abs }}$ values were higher than the relative $L_{\text {down,abs }}$ values during 


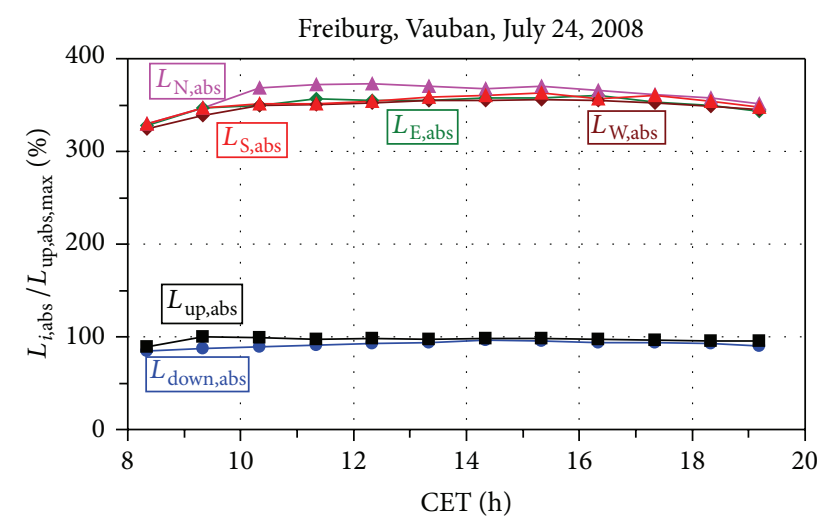

FIgURE 19: $1 \mathrm{~h}$ mean values of the long-wave radiant flux densities $L_{i \text { abs }}(i=$ down, up, E, S, W, and $\mathrm{N}$ ) from the three-dimensional environment absorbed by the human-biometeorological reference person, related to the $1 \mathrm{~h}$ peak value of $L_{\text {up,abs }}\left(L_{\text {up,abs,max }}=28 \mathrm{~W} / \mathrm{m}^{2}\right)$, SSW-facing sidewalk (shaded by tree canopies) of a WNW-ESE street canyon, "Vauban" quarter in Freiburg during typical Central European summer day.

the complete measuring period (Figure 19) but by only $5 \%$ on average, while it was $13 \%$ for the shading by a building. The relative $L_{i \text {,abs }}$ values of the four horizontal directions $i$ were at a higher mean level (350\%) for the shading by tree canopies compared to the mean value of $330 \%$ for the shading by a building. As for this shading method, the reference values $K_{\text {down,abs,max }}\left(25 \mathrm{~W} / \mathrm{m}^{2}\right)$ and $L_{\text {up,abs,max }}\left(28 \mathrm{~W} / \mathrm{m}^{2}\right)$ for the shading by tree canopies were also in a similar range. For both shading options, $L_{\text {up,abs, } \max }$ was by about $3 \mathrm{~W} / \mathrm{m}^{2}$ higher than $K_{\text {down,abs,max }}$, whereby both reference values were slightly higher for the shading by a building.

As both sites of this measuring campaign were located at the same SSW-facing sidewalk (Figure 1), the shading effect of the tree canopies can be determined by a comparison of the results for the shaded and the adjacent sunny site. The peak values of the differences $\Delta$ for the same variables like in Figure 11 between both sites are $\Delta T_{a}=-1.7^{\circ} \mathrm{C}, \Delta T_{\mathrm{mrt}}$ $=-32.8^{\circ} \mathrm{C}$, and $\triangle \mathrm{PET}=-15.7^{\circ} \mathrm{C}$ (Figure 20). Compared to the $\Delta$ values for the shading by a building, the shading by tree canopies caused slightly higher peak values of $\Delta T_{\mathrm{mrt}}$ and consequently also for $\triangle \mathrm{PET}$, while the peak value for $\Delta T_{a}$ was equal for both shading conditions. With respect to the physical processes, which are related to the shading by tree canopies, it is understandable that $\Delta$ was the strongest at the early afternoon for each of the three selected human-biometeorological variables.

Related to the mean values of $T_{a}, T_{\text {mrt }}$, and PET over 12$15 \mathrm{CET}$, that is, the period where the shading was effective during both measuring campaigns, the maximal relative reduction $\Delta$ (Table 3 ) was equal for $T_{a}(6 \%)$. However, it was slightly higher for $T_{\text {mrt }}$ (51\%) and PET (41\%) in the case of shading by tree canopies compared to $\Delta T_{\mathrm{mrt}}(47 \%)$ and $\Delta \mathrm{PET}$ (31\%) for shading by a building.

In contrast to the measuring campaign on July 15, 2007, the peak difference between $T_{\mathrm{mrt}}$ and $T_{a}\left(39.9^{\circ} \mathrm{C}\right)$ for the measuring campaign on July 24,2008 , which occurred in

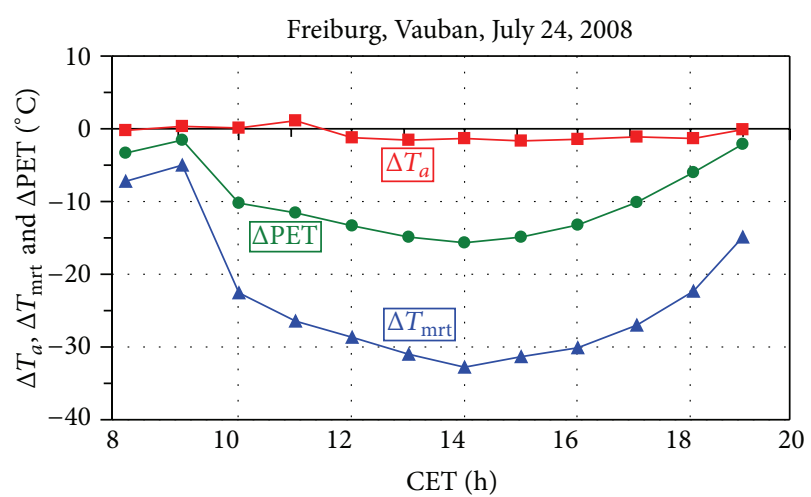

Figure 20: $1 \mathrm{~h}$ mean values of differences $\Delta$ of air temperature $T_{a}$, mean radiant temperature $T_{\mathrm{mrt}}$, and physiologically equivalent temperature PET between a shaded (by tree canopies) and sunny SSW-facing sidewalk of a WNW-ESE street canyon, "Vauban" quarter in Freiburg during typical Central European summer day.

TABLE 3: Maximal relative reduction $\Delta$ of $T_{a}, T_{\text {mrt }}$, and PET by two shading methods related to the mean values of $T_{a}, T_{\text {mrt }}$, and PET over 12-15 CET, based on results of both human-biometeorological measuring campaigns in Freiburg during typical Central European summer weather.

\begin{tabular}{lccc}
\hline Shading methods & $\Delta T_{a}$ & $\Delta T_{\text {mrt }}$ & $\Delta$ PET \\
\hline Shading by a building (July 15, 2007) & $6 \%$ & $47 \%$ & $31 \%$ \\
Shading by tree canopies (July 24, 2008) & $6 \%$ & $51 \%$ & $41 \%$ \\
\hline
\end{tabular}

the afternoon, was distinctly higher at the sunny SSW-facing sidewalk. For the shaded SSW-facing sidewalk, the peak difference $\left(31.2^{\circ} \mathrm{C}\right)$ was observed in the morning before the shading effect started. The longer lasting shading in the measuring campaign of July 24, 2008 was responsible for the continuous decrease of the normalized $\left(T_{\mathrm{mrt}}-T_{a}\right)$ values from $30 \%$ around $10 \mathrm{CET}$ to $5 \%$ in the late afternoon (Figure 21 ). At the sunny SSW-facing sidewalk, the values of the normalized $\left(T_{\mathrm{mrt}}-T_{a}\right)$ started to decrease from the middle of the afternoon. This result is quite similar to those obtained for the comparable SSW-facing sidewalk in the measuring campaign a year earlier.

As for the measuring campaign in 2007, the differences $\Delta$ of the sums of the short-wave radiant flux densities $\left(K_{\mathrm{abs}}^{*}\right)$ between the shaded and sunny SSW-facing measuring sites were higher (Figure 22) than for the sums of the long-wave radiant flux densities $\left(L_{\mathrm{abs}}^{*}\right)$. For $\Delta K_{\mathrm{abs}}^{*}$, this difference was the strongest with $-193 \mathrm{~W} / \mathrm{m}^{2}$ around $14 \mathrm{CET}$, while the peak value for $\Delta L_{\mathrm{abs}}^{*}$ amounted to $-43 \mathrm{~W} / \mathrm{m}^{2}$ and occurred one hour later. Despite differences of type and structure of the three-dimensional environment at the measuring sites, the peak $\Delta L_{\text {abs }}^{*}$ values do not differ between both measuring campaigns. Two essential reasons for this result, which is somewhat surprising at the first view, are the similar weather conditions and the unchanged orientation of the street canyon.

In contrast to the measuring campaign of 2007, the relative $K_{\mathrm{abs}}^{*}$ values obtained for the sunny sidewalk in the measuring campaign of 2008 slightly exceeded $30 \%$ (Figure 23). The peak value of $34 \%$ in the afternoon was 


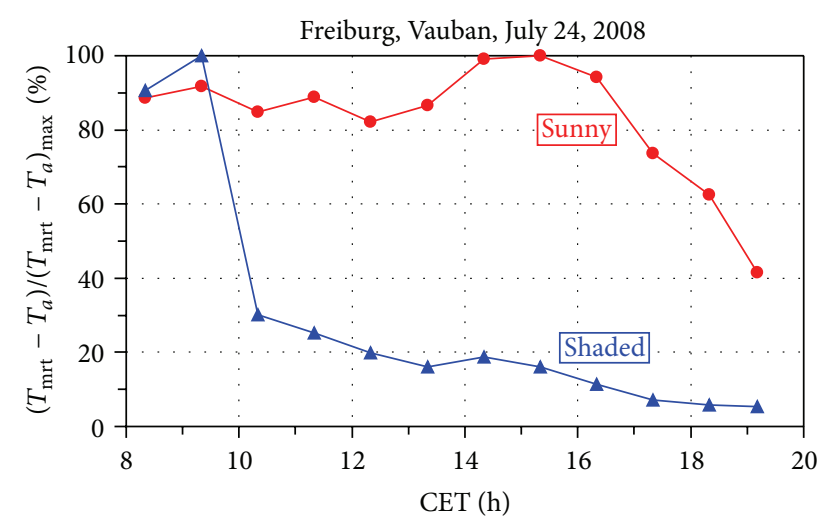

FIgURE 21: $1 \mathrm{~h}$ mean values of the difference between mean radiant temperature $T_{\mathrm{mrt}}$ and air temperature $T_{a}$, related to the $1 \mathrm{~h}$ peak value of $\left(T_{\mathrm{mrt}}-T_{a}\right)$ at the shaded $\left(\left(T_{\operatorname{mrt}}-T_{a}\right)_{\max }=31.2^{\circ} \mathrm{C}\right)$ and sunny $\left(\left(T_{\operatorname{mrt}}-T_{a}\right)_{\max }=39.9^{\circ} \mathrm{C}\right) \mathrm{SSW}$-facing sidewalk of a WNWESE street canyon, "Vauban" quarter in Freiburg during typical Central European summer day.



FIGURE 22: $1 \mathrm{~h}$ mean values of differences $\Delta$ of the sums of short-wave radiant flux densities $\left(K_{\mathrm{abs}}^{*}\right)$ and long-wave radiant flux densities $\left(L_{\mathrm{abs}}^{*}\right)$ from the three-dimensional environment absorbed by the human-biometeorological reference person between the shaded (by tree canopies) and sunny SSW-facing sidewalk of a WNW-ESE street canyon, "Vauban" quarter in Freiburg during typical Central European summer day.

equivalent to a minimum value for the relative $L_{\text {abs }}^{*}$ of $66 \%$. The shading by tree canopies caused a continuous decrease of the relative $K_{\mathrm{abs}}^{*}$ from $8 \%$ at the beginning of the shading up to $1 \%$ in the late afternoon. Accordingly, the relative $L_{\mathrm{abs}}^{*}$ increased from $92 \%$ to $99 \%$. During the complete afternoon, the relative $L_{\text {abs }}^{*}$ values for the shaded situation in 2008 were above $94 \%$, which was the level under the shading condition by a building in 2007 .

3.3. Discussion. Among several human-biometeorological experiments conducted during comparable weather conditions, that is, on typical Central European summer days, in different quarters of Freiburg from 2007-2010, two 1-day campaigns were selected to achieve generalizable results for the objectives of this study. Up to now, they were already known qualitatively, but these experiments enabled their

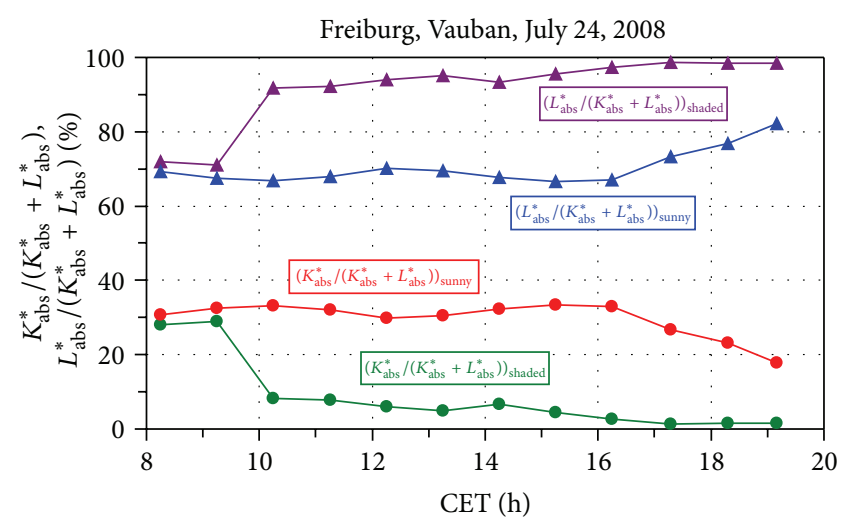

FIgURE 23: $1 \mathrm{~h}$ mean values of the sums of short-wave radiant flux densities $\left(K_{\mathrm{abs}}^{*}\right)$ and long-wave radiant flux densities $\left(L_{\mathrm{abs}}^{*}\right)$ from the three-dimensional environment absorbed by the humanbiometeorological reference person, related to $1 \mathrm{~h}$ mean values of $\left(K_{\mathrm{abs}}^{*}+L_{\mathrm{abs}}^{*}\right)$, at the shaded (by tree canopies) and sunny SSWfacing sidewalk of a WNW-ESE street canyon, "Vauban" quarter in Freiburg during typical Central European summer day.

TABle 4: Coefficient of determination $R^{2}$ of linear regression functions $f$ between $1 \mathrm{~h}$ mean values of different humanbiometeorological variables, basis: experimental investigations on typical Central European summer days in various urban quarters of Freiburg from 2007-2010 ( $n$ : number of values).

\begin{tabular}{lcc}
\hline function $f$ & $R^{2}$ \\
& $\begin{array}{c}10-16 \text { CET } \\
n=200\end{array}$ & $\begin{array}{c}22-5 \text { CET } \\
n=40\end{array}$ \\
\hline $\mathrm{PET}=f\left(T_{\mathrm{mrt}}\right)$ & 0.892 & 0.616 \\
$\mathrm{PET}=f\left(T_{a}\right)$ & 0.589 & 0.892 \\
$\mathrm{PET}=f(\mathrm{VP})$ & 0.023 & 0.006 \\
$\mathrm{PET}=f(v)$ & 0.029 & 0.013 \\
$T_{\mathrm{mrt}}=f\left(T_{a}\right)$ & 0.308 & 0.825 \\
\hline
\end{tabular}

quantification in a reliable way. By discussing the short- and long-wave radiant flux densities from the three-dimensional surroundings in detail, a deeper insight was provided into the radiation exchange. This is necessary for the physical understanding of the behaviour of $T_{\text {mrt }}$ under different local environments.

Based on all human-biometeorological experiments in Freiburg concerning human heat stress during typical Central European summer weather, the results of a statistical analysis show that in the daytime PET was strongly governed by $T_{\text {mrt }}$ (Table 4 ). This relationship was already indicated by the results of both case studies, which mainly addressed the variability of $T_{\text {mrt }}$ for two shading methods.

During the daytime hours from 10-16 CET, that is, the period when citizens are badly affected by outdoor heat stress, the coefficient of determination $R^{2}$ of the linear regression between $1 \mathrm{~h}$ mean values of PET $\left({ }^{\circ} \mathrm{C}\right)$ and $T_{\text {mrt }}\left({ }^{\circ} \mathrm{C}\right)$

$$
\mathrm{PET}=0.581 \cdot T_{\mathrm{mrt}}+8.2
$$

was 0.892; that is, it was clearly higher than for the linear regression between PET and $T_{a}(0.589)$. 


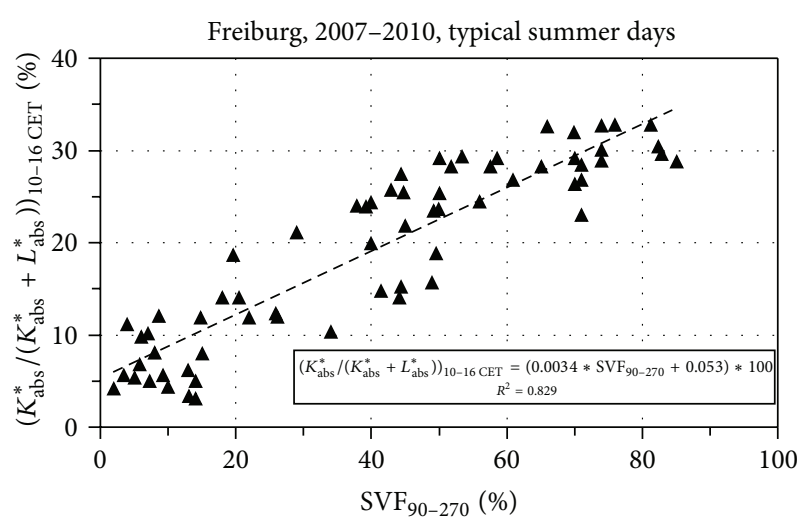

FIGURE 24: Relationship between mean values (10-16 CET) of $\left(K_{\mathrm{abs}}^{*} /\left(K_{\mathrm{abs}}^{*}+L_{\mathrm{abs}}^{*}\right)\right)$ and $\mathrm{SVF}_{90-270}$, based on human-biometeorological measuring campaigns at different sites in Freiburg on typical summer days 2007-2010.

The distinctly lower significance of $T_{a}$ and consequently of the urban heat island intensity for PET in the daytime was caused by the human-biometeorological assessment method for thermal comfort. It can be interpreted as a nesting of a smaller volume, that is, the volume of the standing humanbiometeorological reference person, into the larger volume of an urban street canyon [13]. The thermal conditions within the latter volume can be described by $T_{a}$. As the human heat budget represents the thermophysiological basis for the perception of outdoor heat by citizens, additional processes besides those, which are responsible for $T_{a}$, have to be taken into account for the smaller volume. They are included in human-biometeorological variables like $T_{\mathrm{mrt}}$ or PET.

The relatively low $R^{2}$ values of the regressions between PET and vapour pressure VP as well as PET and wind speed $v$ point out that the prevailing VP and $v$ conditions during typical Central European summer weather just play a minor part for the human perception of heat in inland cities expressed by PET.

At night, the radiation exchange only consists of longwave radiant flux densities. Therefore, $R^{2}$ of the linear regression between $T_{\mathrm{mrt}}$ and $T_{a}$ was distinctly higher in the period 22-5 CET (0.825) than that for the daytime period 1016 CET (0.308). As a result, $R^{2}$ was the highest in the night for the linear regression between PET and $T_{a}(0.892)$.

This investigation in terms of two 1-day human-biometeorological experiments has shown that human thermal stress in the daytime indicated by PET can be reduced in the local urban scale, if the direct solar radiation is decreased by shading, which itself influences another short- and some long-wave radiant flux densities. As previously mentioned, $\mathrm{SVF}_{90-270}$ represents a suitable measure to characterize the spatial extent of shading in terms of urban human-biometeorology. A decreasing $\mathrm{SVF}_{90-270}$ indicates an increase of the spatial extent of shading in the southern half of the upper hemisphere.

Based on data of all measurement campaigns mentioned in Table 4, the mean relative $K_{\mathrm{abs}}^{*}$ determined for the period $10-16$ CET linearly decreased with a lowering of $\mathrm{SVF}_{90-270}$

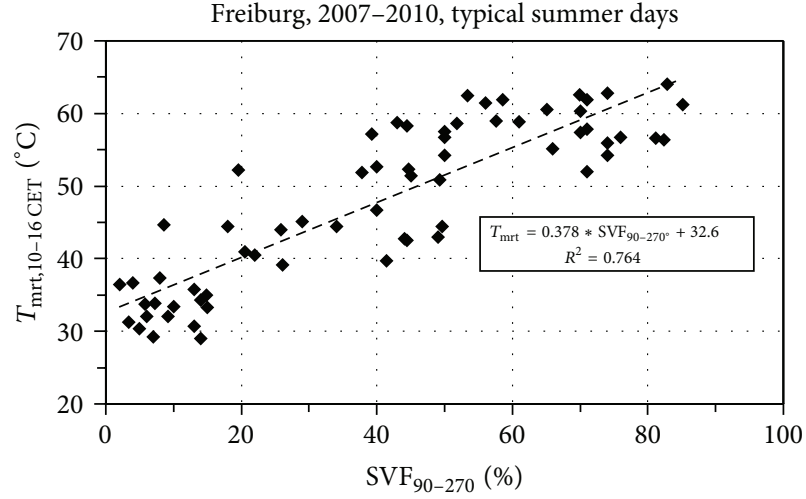

FIGURE 25: Relationship between mean values (10-16 CET) of $T_{\text {mrt }}$ and $\mathrm{SVF}_{90-270}$, based on human-biometeorological measuring campaigns at different sites in Freiburg on typical summer days 2007-2010 [2].

(Figure 24). This means that the mean relative $L_{\mathrm{abs}}^{*}$ over the same period increased with a lowering of $\mathrm{SVF}_{90-270}$. As $T_{\mathrm{mrt}}$ depends on the sum of $K_{\mathrm{abs}}^{*}$ and $L_{\mathrm{abs}}^{*}(1)$, the contribution of relative $L_{\mathrm{abs}}^{*}$ for $T_{\mathrm{mrt}}$ was linearly increasing with decreasing $\mathrm{SVF}_{90-270}$. However, it should be borne in mind that shading decreased the absolute values of both $K_{\mathrm{abs}}^{*}$ and $L_{\mathrm{abs}}^{*}$, whereby this decrease was stronger for $K_{\mathrm{abs}}^{*}$ than for $L_{\mathrm{abs}}^{*}$. Shading in terms of lower $\mathrm{SVF}_{90-270}$ also led to a lower absolute sum $\left(K_{\mathrm{abs}}^{*}+L_{\mathrm{abs}}^{*}\right)$. Due to the dependence of $T_{\mathrm{mrt}}$ on this sum, a decreasing $\mathrm{SVF}_{90-270}$ also caused a lower $T_{\text {mrt }}$ [2], whereby the relationship can be approximated by linear regression (Figure 25).

In the human-biometeorological concept to assess the thermal environment, the standing position of the reference person leads to a higher significance of the horizontal radiant flux densities. However, shading of the direction-dependent solar radiation also has consequences for the other radiant flux densities. Different shading methods mainly influence the short- and long-wave radiant flux densities directly in the spatial range of the shading device. Its extent varies dependent on the solar altitude, that is, time of day and year.

Due to the substantial significance of the horizontal radiant flux densities for the determination of $T_{\text {mrt }}$ and consequently PET during summer weather, a simulation for an E-W street canyon $(H / W=1)$ with similar buildings at both sides was performed using the ENVI-met model. Related to the meteorological conditions of a day during the Central European heat wave of 2003, the results show that an extreme change of the albedo of the vertical walls of both buildings from 0.1 to 0.9 leads to modifications of short- and long-wave radiant flux densities, which result in an increase of $T_{\text {mrt }}$ up to $30^{\circ} \mathrm{C}$. This is mainly caused by the higher shortwave radiant flux densities reflected from the vertical walls. This result, which seems to be surprising at first view, does not agree with other investigations on the influence of changed albedo performed with the Green CTTC model [31], as they show a decrease of $T_{\text {mrt }}$ with an increase of the albedo of vertical walls. 


\section{Conclusions}

Among several human-biometeorological measuring campaigns conducted from 2007-2010 within different urban quarters in Freiburg during typical Central European summer weather, two measuring campaigns were selected in order to analyze the response of the human-biometeorological variables $T_{a}, T_{\mathrm{mrt}}$, and PET on the shading of the direct solar radiation by (i) a building and (ii) tree canopies. As $T_{\text {mrt }}$ and consequently PET reflect the shading effects much stronger than $T_{a}$, the behaviour of the short- and long-wave radiant flux densities from the three-dimensional environment, which are the basis to calculate $T_{\text {mrt }}$, was investigated in detail. Related to all human-biometeorological measuring campaigns in Freiburg, the achieved results for the two case studies have a general validity, because their weather conditions were always quite similar.

Results from regional climate simulations project for Central Europe that extreme summer heat like in 2003 will be the normality as from $2050[3,4]$. By providing physical data, which can be used for the explanation of shading impacts and the preliminary fixing of specific shading devices, for example, with respect to its type or duration, this investigation contributes to the discussion on the effectiveness of shading impacts on maintaining human thermal comfort even under extreme summer heat.

Another advantage of this applied investigation design is the availability of reliable data on the short- and longwave radiant flux densities from the three-dimensional environment, which can be used for the validation of results of simulation models for the three-dimensional radiation field within urban structures $[24,28]$. This validation can lead to an update of the physical basis of the models, which is recommended to improve the accuracy of their results $[35,38]$.

The synopsis of all human-biometeorological experiments conducted during Central European summer weather in different urban structures of Freiburg from 2007-2010 points out that shading in terms of $\mathrm{SVF}_{90-270}$ causes not only lower relative $K_{\mathrm{abs}}^{*}$ and, therefore, higher relative $L_{\mathrm{abs}}^{*}$ values but also lower absolute values of the sum $\left(K_{\mathrm{abs}}^{*}+L_{\mathrm{abs}}^{*}\right)$. They are responsible for the decrease of $T_{\text {mrt }}$ with lower $\mathrm{SVF}_{90-270}$. The analysis of all experimental results in terms of mean values for the period from 10 to 16 CET shows that a reduction of $\mathrm{SVF}_{90-270}$ by $10 \%$ through shading by tree canopies leads to a lowering of $T_{a}$ by $0.2^{\circ} \mathrm{C}, T_{\mathrm{mrt}}$ by $3.8^{\circ} \mathrm{C}$, and PET by $1.4^{\circ} \mathrm{C}$. These communal benefits are qualitatively visualized by Figure 26.

\section{Acknowledgments}

For the grants given to this research, the authors are indebted to the German Federal Ministry of Education and Research (BMBF), Project KLIMES ALUF (FZK: 01LS05020) within the scope of the research initiative "klimazwei," and the German-Israeli Foundation for Scientific Research and Development (GIF) under Grant no. 955-36.8/2007. The authors also give thanks to students and colleagues of the Meteorological Institute, Albert-Ludwigs-University

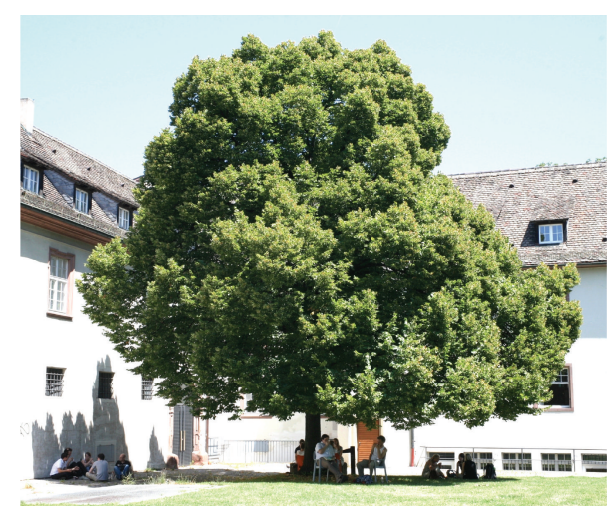

FIGURE 26: Human thermal comfort below the canopy of a vital linden tree on a typical Central European summer day (June 27, 2011) in Freiburg.

of Freiburg, who supported the human-biometeorological measurements. The ENVI-met simulation reported in this study was conducted by Matthias Mühleis.

\section{References}

[1] H. Mayer, J. Holst, P. Dostal, F. Imbery, and D. Schindler, "Human thermal comfort in summer within an urban street canyon in central Europe," Meteorologische Zeitschrift, vol. 17, no. 3, pp. 241-250, 2008.

[2] J. Holst and H. Mayer, "Impacts of street design parameters on human-biometeorological variables," Meteorologische Zeitschrift, vol. 20, no. 5, pp. 541-552, 2011.

[3] J. Ballester, X. Rodó, and F. Giorgi, "Future changes in central Europe heat waves expected to mostly follow summer mean warming," Climate Dynamics, vol. 35, no. 7, pp. 1191-1205, 2010.

[4] J. Ballester, F. Giorgi, and X. Rodó, "Changes in European temperature extremes can be predicted from changes in PDF central statistics," Climatic Change, vol. 98, no. 1-2, pp. 277-284, 2010.

[5] R. S. Kovats and S. Hajat, "Heat stress and public health: a critical review," Annual Review of Public Health, vol. 29, pp. 4155, 2008.

[6] S. N. Gosling, J. A. Lowe, G. R. McGregor, M. Pelling, and B. D. Malamud, "Associations between elevated atmospheric temperature and human mortality: a critical review of the literature," Climatic Change, vol. 92, no. 3-4, pp. 299-341, 2009.

[7] Federal Statistical Office of Germany, "Demographic change in Germany-issue 2011,” Tech. Rep. 1, 2011.

[8] C. S. B. Grimmond, M. Roth, T. R. Oke et al., "Climate and more sustainable cities: climate information for improved planning and management of cities (producers/capabilities perspective)," Procedia Environmental Sciences, vol. 1, pp. 247-274, 2010.

[9] E. Ng, "Towards planning and practical understanding of the need for meteorological and climatic information in the design of high-density cities: a case-based study of Hong Kong," International Journal of Climatology, vol. 32, no. 4, pp. 582-598, 2012.

[10] W. Kuttler, "Climate change in urban areas-part 2: measures," Environmental Sciences Europe, vol. 23, pp. 1-15, 2011.

[11] W. Kuttler, S. Weber, J. Schonnefeld, and A. Hesselschwerdt, "Urban/rural atmospheric water vapour pressure differences 
and urban moisture excess in Krefeld, Germany," International Journal of Climatology, vol. 27, no. 14, pp. 2005-2015, 2007.

[12] E. Ng, "Policies and technical guidelines for urban planning of high-density cities - air ventilation assessment (AVA) of Hong Kong," Building and Environment, vol. 44, no. 7, pp. 1478-1488, 2009.

[13] J. Holst and H. Mayer, "Urban human-biometeorology: investigations in freiburg (Germany) on human thermal comfort," Urban Climate News, no. 38, pp. 5-10, 2010.

[14] F. Ali-Toudert and H. Mayer, "Numerical study on the effects of aspect ratio and orientation of an urban street canyon on outdoor thermal comfort in hot and dry climate," Building and Environment, vol. 41, no. 2, pp. 94-108, 2006.

[15] F. Ali-Toudert and H. Mayer, "Effects of asymmetry, galleries, overhanging façades and vegetation on thermal comfort in urban street canyons," Solar Energy, vol. 81, no. 6, pp. 742-754, 2007.

[16] H. Mayer and P. Höppe, "Thermal comfort of man in different urban environments," Theoretical and Applied Climatology, vol. 38, no. 1, pp. 43-49, 1987.

[17] N. Kántor and J. Unger, "Benefits and opportunities of adopting GIS in thermal comfort studies in resting places: an urban park as an example," Landscape and Urban Planning, vol. 98, no. 1, pp. 36-46, 2010.

[18] L. Chen and E. Ng, "Outdoor thermal comfort and outdoor activities: a review of research in the past decade," Cities, vol. 29, no. 2, pp. 118-125, 2012.

[19] T.-P. Lin, K.-T. Tsai, R.-L. Hwang, and A. Matzarakis, "Quantification of the effects of thermal indices and sky view factor on park attendance," Landscape and Urban Planning, vol. 107, no. 2, pp. 137-146, 2012.

[20] A. M. Abdel-Ghany, I. M. Al-Helal, and M. R. Shady, "Human thermal comfort and heat stress in an outdoor urban arid environment: a case study," Advances in Meteorology, vol. 2013, Article ID 693541, 7 pages, 2013.

[21] P. Cohen, O. Potchter, and A. Matzarakis, "Human thermal perception of Coastal Mediterranean outdoor urban environments," Applied Geography, vol. 37, no. 1, pp. 1-10, 2013.

[22] D. Fröhlich and A. Matzarakis, "Modelling of changes in thermal bioclimate: examples based on urban spaces in Freiburg, Germany," Theoretical and Applied Climatology, vol. 111, no. 3-4, pp. 547-558, 2013.

[23] G. Jendritzky, R. de Dear, and G. Havenith, "UTCI-Why another thermal index?" International Journal of Biometeorology, vol. 56, no. 3, pp. 421-428, 2012.

[24] A. Matzarakis, F. Rutz, and H. Mayer, "Modelling radiation fluxes in simple and complex environments: basics of the RayMan model," International Journal of Biometeorology, vol. 54, no. 2, pp. 131-139, 2010.

[25] L. Shashua-Bar, D. Pearlmutter, and E. Erell, "The influence of trees and grass on outdoor thermal comfort in a hot-arid environment," International Journal of Climatology, vol. 31, no. 10, pp. 1498-1506, 2011.

[26] D. E. Bowler, L. Buyung-Ali, T. M. Knight, and A. S. Pullin, "Urban greening to cool towns and cities: a systematic review of the empirical evidence," Landscape and Urban Planning, vol. 97, no. 3, pp. 147-155, 2010.

[27] T.-P. Lin, A. Matzarakis, and R.-L. Hwang, "Shading effect on long-term outdoor thermal comfort," Building and Environment, vol. 45, no. 1, pp. 213-221, 2010.

[28] F. Lindberg and C. S. B. Grimmond, "The influence of vegetation and building morphology on shadow patterns and mean radiant temperatures in urban areas: model development and evaluation," Theoretical and Applied Climatology, vol. 105, no. 34, pp. 311-323, 2011.

[29] S. Oliveira, H. Andrade, and T. Vaz, "The cooling effect of green spaces as a contribution to the mitigation of urban heat: a case study in Lisbon," Building and Environment, vol. 46, no. 11, pp. 2186-2194, 2011.

[30] G. Gross, "Effects of different vegetation on temperature in an urban building environment. micro-scale numerical experiments," Meteorologische Zeitschrift, vol. 21, no. 4, pp. 399-412, 2012.

[31] L. Shashua-Bar, I. X. Tsiros, and M. Hoffman, "Passive cooling design options to ameliorate thermal comfort in urban streets of a mediterranean climate (athens) under hot summer conditions," Building and Environment, vol. 57, pp. 110-119, 2012.

[32] S. Leuzinger, R. Vogt, and C. Körner, "Tree surface temperature in an urban environment," Agricultural and Forest Meteorology, vol. 150, no. 1, pp. 56-62, 2010.

[33] P. Höppe, "The physiological equivalent temperature-a universal index for the biometeorological assessment of the thermal environment," International Journal of Biometeorology, vol. 43, no. 2, pp. 71-75, 1999.

[34] P. Höppe, "A new method to determine the mean radiant temperature outdoors," Wetter und Leben, vol. 44, no. 1-3, pp. 147-151, 1992.

[35] S. Thorsson, F. Lindberg, I. Eliasson, and B. Holmer, "Different methods for estimating the mean radiant temperature in an outdoor urban setting," International Journal of Climatology, vol. 27, no. 14, pp. 1983-1993, 2007.

[36] N. Kántor, L. Égerházi, and J. Unger, "Subjective estimation of thermal environment in recreational urban spaces-part 1: investigations in Szeged, Hungary," International Journal of Biometeorology, vol. 56, no. 6, pp. 1075-1088, 2012.

[37] S. Oliveira and H. Andrade, "An initial assessment of the bioclimatic comfort in an outdoor public space in Lisbon," International Journal of Biometeorology, vol. 52, no. 1, pp. 69-84, 2007.

[38] N. Kántor and J. Unger, “The most problematic variable in the course of human-biometeorological comfort assessmentthe mean radiant temperature," Central European Journal of Geosciences, vol. 3, no. 1, pp. 90-100, 2011.

[39] S. Thorsson, M. Lindqvist, and S. Lindqvist, "Thermal bioclimatic conditions and patterns of behaviour in an urban park in Göteborg, Sweden," International Journal of Biometeorology, vol. 48, no. 3, pp. 149-156, 2004.

[40] N. Kántor, J. Unger, and Á. Gulyas, "Subjective estimations of thermal environment in recreational urban spaces-part 2: international comparison," International Journal of Biometeorology, vol. 56, no. 6, pp. 1089-1101, 2012.

[41] T.-P. Lin, "Thermal perception, adaptation and attendance in a public square in hot and humid regions," Building and Environment, vol. 44, no. 10, pp. 2017-2026, 2009.

[42] E. Ng and V. Cheng, "Urban human thermal comfort in hot and humid Hong Kong," Energy and Buildings, vol. 55, pp. 51-65, 2012.

[43] A. Matzarakis and H. Mayer, "Another kind of environmental stress: thermal stress," WHO Newsletter, vol. 18, pp. 7-10, 1996.

[44] G. Jendritzky, W. Sönning, and H. J. Swantes, "An objective evaluation method for the description of the thermal surroundings in urban and landscape planning ("Klima-Michel-Modell")," Academy Spatial Research Planning Report 28, 1979.

[45] J. Konarska, F. Lindberg, A. Larsson, S. Thorsson, and B. Holmer, "Transmissivity of solar radiation through the crowns of single urban trees," Urban Climate News, no. 46, pp. 20-24, 2012. 

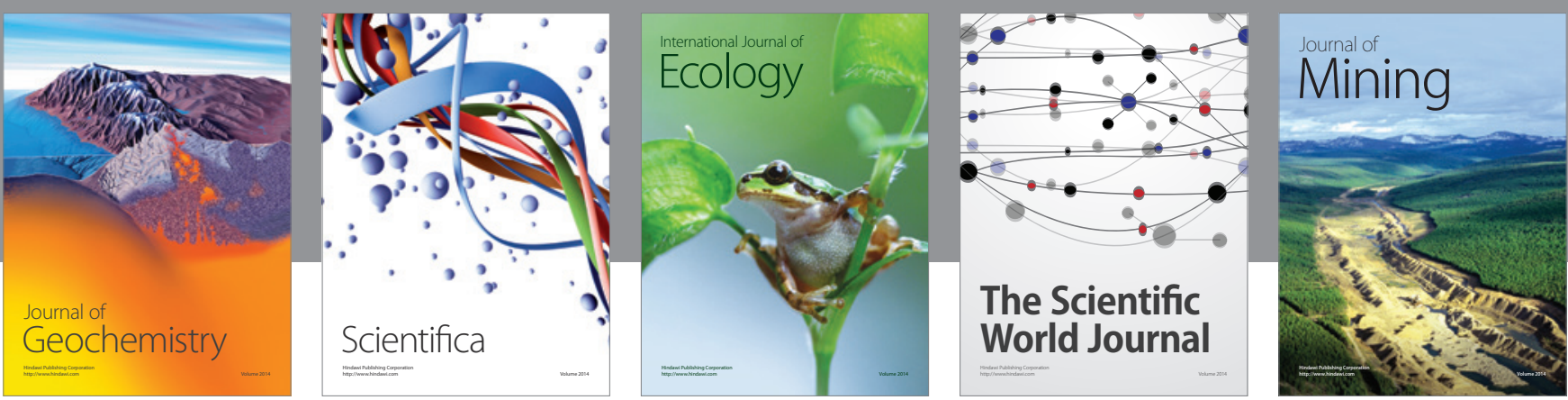

The Scientific World Journal
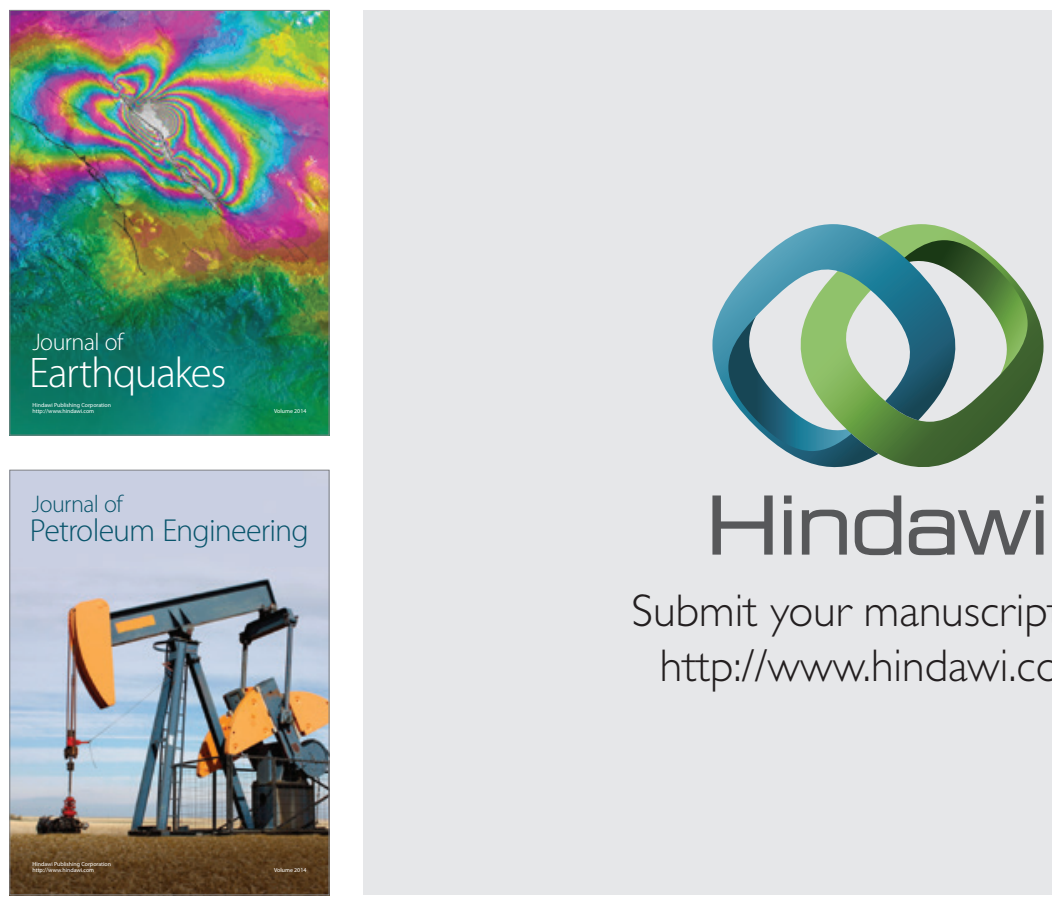

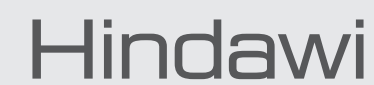

Submit your manuscripts at

http://www.hindawi.com
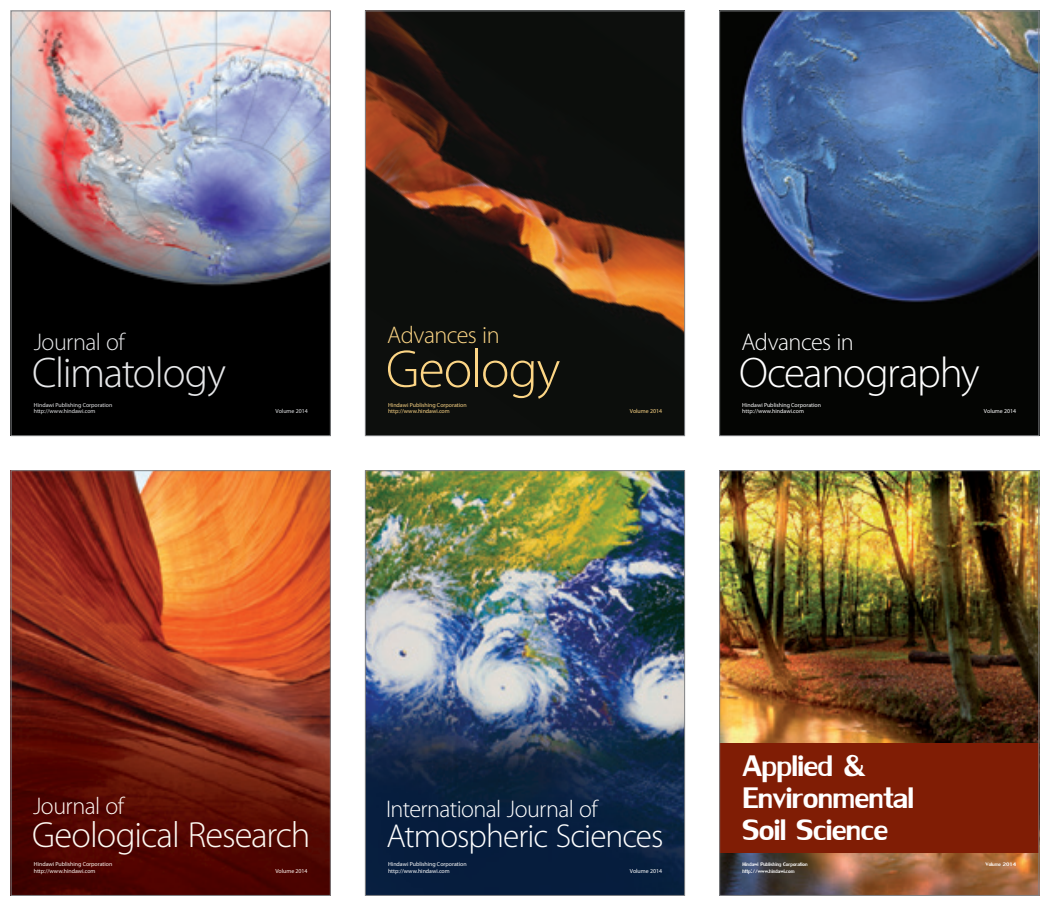
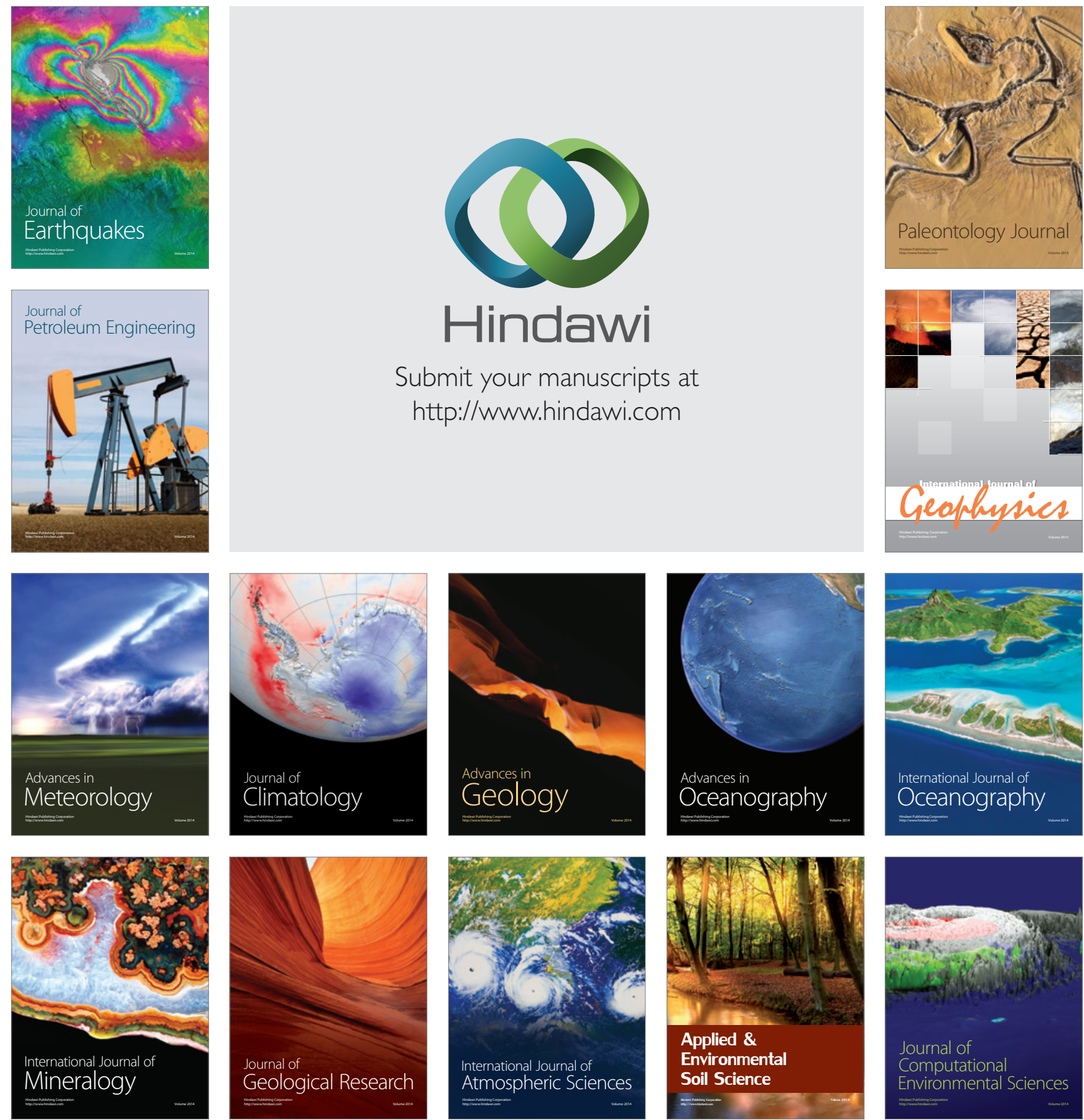